\title{
Colonización bacteriana de piel sana versus quemada de niños bajo 15 años tratados en COANIQUEM, Santiago de Chile
}

\author{
María T. Ulloa F., Loriana Castillo D., Fresia Solís F., Gabriela Arévalo P. y Jorge Rojas Z.
}

\section{Bacterial colonization in areas of burnt skin and healthy children younger than 15 years, seen COANIQUEM, Santiago, Chile}

Bacterial colonization in patients with burns skin without infection and outpatient management has been poorly studied. Objective: To quantify and identify the type of bacteria that colonize healthy body areas homologous location of the skin in children from 1 to 15 years, seen COANIQUEM, Santiago, Chile. Per patient, we studied 204 samples from each zone. The isolated microorganisms were S. epidermidis 35, 3\%; others Staphylococcus coagulase negative, $25.8 \%$; S. aureus, $4.4 \%$; and S. viridans group $1.4 \%$. In the subgroup of children who had a count between 1 and $1000 \mathrm{cfu}$, there was a higher proportion of cfu in burned skin healthy skin $(\mathrm{p}=0.0359)$. The association between depth of the lesion and the bacterial count obtained $p=0.034$. Conclusion: In outpatient treatment, the microorganisms are expected in healthy skin, burned skin is evident in lower counts probably associated with epithelial damage.

Key words: Bacterial colonization, burnt skin, healthy skin, children

Palabras clave: Colonización bacteriana, piel quemada, piel sana, niños

\section{Introducción}

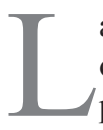

a piel representa la primera barrera defensiva del organismo frente al acceso de los microorganismos presentes en el medio ambiente. En forma paradójica, una de las características que la hacen comportarse como una barrera tan eficiente es la microbiota comensal que se establece y la coloniza desde el nacimiento, en densidades que varían dependiendo de la zona del cuerpo, de la edad, el pH y la humedad, entre otros factores. En condiciones fisiológicas, la microbiota comensal impide la colonización de la piel por otras especies bacterianas a través del mecanismo de interferencia bacteriana, el cual evita, de forma muy eficiente, el establecimiento de microorganismos oportunistas y/o patógenos ${ }^{1}$.

Las quemaduras implican la pérdida de esta barrera defensiva, permitiendo la colonización de la superficie cruenta por microorganismos oportunistas o patógenos, provenientes principalmente de otros territorios del cuerpo o del ambiente. Esta colonización bacteriana suele preceder a la invasión de los tejidos adyacentes a la quemadura y en algunos casos, al torrente sanguíneo, desarrollándose una infección local y/o sistémica ${ }^{2}$.

Diversos estudios describen los agentes etiológicos de infección en pacientes quemados. Uno de éstos fue realizado por la Corporación de Ayuda al Niño Quemado (COANIQUEM), entre 2000-2004, en un total de 387 niños con infección por quemadura. Las muestras se obtuvieron por hisopado de la quemadura infectada con tórula de algodón y los microorganismos aislados fueron: Staphylococcus aureus (48,1\%); Staphylococcus coagulasa negativa (45,9\%); Escherichia coli, (2\%); Pseudomonas spp. (1,2\%); Streptococcus spp. (1,5\%); Proteus spp $(0,5 \%)$ y Candida $\operatorname{spp}(0,2 \%)$. (Arévalo G. Comunicación personal). Si bien es cierto, la técnica "patrón de oro" para identificar y cuantificar los microorganismos involucrados en la infección de las quemaduras es el cultivo cuantitativo de la biopsia de tejido, dicha técnica no estaría justificada en el caso de quemaduras infectadas de manejo ambulatorio, especialmente tratándose de niños, por lo cruenta que resulta la obtención de la muestra y porque existen varios estudios que evidencian una buena correlación entre el cultivo cuantitativo de biopsia y el cultivo cuantitativo y semicuantitativo de muestras obtenidas mediante el hisopado con tórula de la superficie quemada $^{3}$. La colonización bacteriana que precede a la infección de las quemaduras de manejo ambulatorio ha sido escasamente estudiada, siendo el objetivo del presente estudio identificar y cuantificar las bacterias que colonizan las quemaduras no infectadas y compararlo con las que colonizan la piel sana de localización homóloga en niños que reciben manejo ambulatorio.

\section{Pacientes y Método}

Pacientes. Se realizó un estudio descriptivo y prospectivo al que ingresaron 204 niños de ambos sexos, entre uno y 15 años de edad, que consultaron en la policlínica

\author{
Universidad de Chile, \\ Santiago. \\ Facultad de Medicina \\ Instituto de Ciencias Biomédicas \\ (MTU). \\ Hospital Clínico Mutual de \\ Seguridad, Santiago, Chile. \\ (LCD). \\ Corporación de Ayuda al \\ Niño Quemado (COANIQUEM), \\ Santiago, Chile. (FSF, GAP, JRZ).
}

Los autores declaran que no existen conflictos de interés.

Fuente de financiamiento: DEDI, COANIQUEM

Recibido: 14 de marzo de 2011 Aceptado: 13 de octubre de 2011

\section{Correspondencia a:}

María Teresa Ulloa Flores mtulloa@med.uchile.cl 
de agudos de COANIQUEM de Santiago, entre octubre 2005 y junio 2008, previo consentimiento informado de los padres. Los criterios de inclusión de pacientes fueron los siguientes:

- Zona de la quemadura: tórax, abdomen y extremidades superiores e inferiores (se excluyeron las quemaduras de manos y pies).

- Profundidad de la quemadura: Superficial (tipo A); intermedia (tipo AB, ABA) y profunda (tipo B, ABB).

- Extensión de la quemadura: $\leq 5 \% 0^{4-6}$, debiendo tener el área quemada una superficie mínima de $10,5 \mathrm{~cm}^{2}$.

- Agente causal de la quemadura: todos, excepto electricidad.

- Tiempo de evolución de la quemadura: hasta 72 horas, dado que el estudio contempla colonización de quemaduras no infectadas.

- Intervenciones aceptadas: Máximo una curación realizada en el lugar inicial de atención del niño, antes del ingreso a COANIQUEM.

Obtención de muestra: En la primera atención en COANIQUEM, la curación de la piel quemada se realizó con suero fisiológico ( $\mathrm{NaCl}$ 9\%o) estéril. Las muestras para cultivo desde la zona quemada y desde el sitio homólogo de piel sana fueron obtenidas mediante hisopado sobre una superficie de $10,5 \mathrm{~cm}^{2}$, con una tórula de dacrón que se frotó por cinco veces, mediante movimientos ascendentes y descendentes, sobre la superficie de piel quemada demarcada previamente, infringiendo a la tórula una presión que permitiera un buen contacto con la superficie quemada. La superficie del área para la toma de muestra se decidió con base al tamaño mínimo que debían tener las quemaduras que ingresan al estudio. Las muestras fueron obtenidas por enfermeras de COANIQUEM con experiencia promedio de 10 años en el manejo de pacientes quemados, mediante el siguiente procedimiento:

- Demarcación de un área de $10,5 \mathrm{~cm}^{2}$ que incluyera la quemadura de mayor profundidad, con diámetro mínimo de $3 \mathrm{~cm}$.

- Frotación del área demarcada con una tórula de dacrón.

- Introducción de la tórula en un tubo estéril con $1 \mathrm{ml}$ de suero fisiológico estéril.

- Repetición del mismo procedimiento en la superficie de piel sana, homóloga a la zona quemada desde la cual se tomó la anterior muestra.

- Transporte de ambas muestras de inmediato al Laboratorio de Bacteriología.

Estudio microbiológico: Se realizó en el Laboratorio de Bacteriología de COANIQUEM e incluyó lo siguiente: recuento bacteriano, identificación de microorganismos y estudio de susceptibilidad in vitro.

Recuento bacteriano: Las muestras de la zona cruenta y de la zona de piel sana fueron homogenizadas en vórtex durante 10 segundos. Posteriormente se realizaron diluciones con base 10 , desde 10 hasta $10^{-5}$. De cada dilución se sembró $100 \mu \mathrm{L}$, en placa de agar sangre cordero $5 \%$ (PAS) y en placa de agar Mac Conkey (PAM) respectivamente, diseminando el inóculo con rastrillo por toda la superficie de la placa. Las PAS fueron incubadas a $35^{\circ} \mathrm{C}$, en atmósfera de $\mathrm{CO}_{2} 3-5 \%$ y las $\mathrm{PAM}$ a $35^{\circ} \mathrm{C}$, en atmósfera normal, durante 24 a 48 horas. El recuento bacteriano se informó como unidades formadoras de colonia por 10,5 $\mathrm{cm}^{2}\left(\mathrm{ufc} / 10,5 \mathrm{~cm}^{2}\right)$.

Identificación de microorganismos: La identificación de M.O. se realizó según protocolos de laboratorio aceptados internacionalmente. Por su importancia en la microbiota normal de la piel, consideramos relevante separar Staphylococcus epidermidis del resto de las especies de Staphylococcus coagulasa negativa. La identificación de $S$. epidermidis se realizó mediante la determinación de catalasa, coagulasa y utilización de carbohidratos mediante metodología tradicional.

Estudio de susceptibilidad antimicrobiana. El perfil de susceptibilidad in vitro de las cocáceas grampositivas se realizó mediante técnica de Kirby-Bauer. Los antimicrobianos analizados fueron: cotrimoxazol 25 $\mu \mathrm{g}$; gentamicina $10 \mu \mathrm{g}$; amoxicilina/ácido clavulánico $30 \mu \mathrm{g}$; oxacilina $1 \mu \mathrm{g}$; tetraciclina $30 \mu \mathrm{g}$; clindamicina $2 \mu \mathrm{g}$; eritromicina $15 \mu \mathrm{g}$ y ciprofloxacina $5 \mu \mathrm{g}$. Como control de calidad del antibiograma, se utilizó $S$. aureus ATCC 25923. Los resultados fueron interpretados según el CLSI $2009^{7}$.

Registro y análisis de los datos: Los datos se registraron en planilla Excel y se procesaron mediante software estadístico SPSS versión 15.0. Se calcularon medidas de resumen y se compararon las proporciones de ufc y tipo de bacteria en piel sana y quemada, mediante prueba de diferencias de proporciones, basado en distribución $\mathrm{Z}$. Se aplica prueba de asociación entre profundidad de la quemadura y recuento de ufc mediante distribución $\chi^{2}$. Todas las pruebas con $\mathrm{p}<0,05$.

\section{Resultados}

Características biodemográficas y clínicas de los pacientes (Tabla 1). Ingresaron al estudio 204 niños. El $75,1 \%$ de los niños tenían menos de 6 años de edad; la distribución de los géneros fue similar (48,6\% mujeres). 98,5\% consultó en Servicios de Urgencia públicos, consultorios u hospitales, previo a su llegada a COANIQUEM. 73,1\% consultó dentro de las primeras 48 horas de ocurrido el episodio. $80,4 \%$ se quemó con líquidos calientes, (volcamiento de taza, hervidor o cocina). 
$34,8 \%$ de las quemaduras se produjeron entre las 20:00 y $24: 00$ horas. $57,3 \%$ de las quemaduras se localizaron en extremidades superiores e inferiores, (exceptuando pie y mano). $85,1 \%$ de las quemaduras tuvieron una extensión $\leq 2 \% .77,5 \%$ correspondió a quemadura intermedia (AB). El manejo domiciliario en $65,2 \%$ de los casos fue lavar la quemadura con agua. El tratamiento médico más aditamento fue el uso de suero fisiológico estéril, ungüento con antimicrobiano y apósito.

Microorganismos aislados. Se estudiaron 204 pares de muestras (piel sana y piel quemada) provenientes del mismo número de pacientes.

- Muestras de piel sana: Hubo desarrollo microbiano en 136 muestras (66,7\%). De las 136 muestras con cultivo positivo se aislaron 138 cepas bacterianas (en 2 muestras hubo 2 aislados).

- Muestras de piel quemada: Hubo desarrollo microbiano en 125 muestras $(61,3 \%)$. De ellas se aislaron 131 cepas bacterianas (en 6 muestras hubo 2 aislados).

Los microorganismos aislados desde muestras de piel sana y quemada se presentan en Tabla 2. No hubo diferencias significativas en la distribución de proporciones entre ambos tipos de muestra $(\mathrm{p}=0,31)$.

No se observó relación entre especie bacteriana aislada con: grupo de edad $(\mathrm{p}=0,096)$; tratamiento casero $(p=0,717)$; agente $(p=0,232)$ ni localización $(p=0,619)$.

Recuento bacteriano. La mayoría de los pacientes, 191/206 (92,7\%) y 192/210 (91,4\%) presentó recuentos bacterianos $<10.000 \mathrm{ufc} / 10,5 \mathrm{~cm}^{2}$ en muestras obtenidas desde piel sana y piel quemada, respectivamente.

En cuatro muestras obtenidas desde piel sana se pesquisaron recuentos $>100.000 \mathrm{ufc} / 10,5 \mathrm{~cm}^{2}$. Ninguna de las muestras obtenidas desde zonas cruentas alcanzó estos recuentos. Los recuentos bacterianos expresados como ufc/10,5 $\mathrm{cm}^{2}$ fueron similares en ambos tipos de muestras $(p=0,11)$. Sin embargo, al analizar el subgrupo entre 1 y 999 ufc/ 10,5 $\mathrm{cm}^{2}$ se observó que fue más frecuente en piel sana $(46,6 \%)$ que en piel quemada $(37,1 \%)$. Aplicada una prueba de diferencia de proporciones de una cola, la diferencia resultó significativa $(\mathrm{p}=0,0359)$ (Tabla 3 ).

Al relacionar la profundidad de la quemadura con el recuento bacteriano, $76 \%$ tenía $<1.000 \mathrm{ufc} / 10,5 \mathrm{~cm}^{2}$; las lesiones por quemadura intermedias o profundas tienen mayor peso relativo. Se prueba asociación entre profundidad de la quemadura y recuento bacteriano, la que resulta significativa $(p=0,034)$, es decir, las proporciones de recuento bacteriano son diferentes de acuerdo con la profundidad de la quemadura (Tabla 4).

Estudio de susceptibilidad in vitro. Las cepas bacterianas aisladas desde las zonas de piel quemada
Tabla 1. Características bio-demográficas y clínicas de niños quemados atendidos en COANIQUEM, Santiago de Chile (n: 204)

\begin{tabular}{|c|c|c|c|c|c|}
\hline Característica & $n^{\circ}$ & $\%$ & Característica & $n^{\circ}$ & $\%$ \\
\hline Género & & & Localización & & \\
\hline Femenino & 102 & 50 & Extremidad superior y mano & 91 & 44,6 \\
\hline Masculino & 102 & 50 & Extremidad inferior y pie & 76 & 37,2 \\
\hline Edad (años) & & & Tórax y abdomen & 33 & 16,2 \\
\hline $1-2$ & 69 & 33,8 & Cara-cuello & 4 & 2 \\
\hline $3-6$ & 82 & 40,2 & Extensión & & \\
\hline $7-10$ & 31 & 15,2 & $<1 \%$ & 113 & 55,4 \\
\hline $11 y+$ & 22 & 10,8 & $1-2 \%$ & 81 & 39,7 \\
\hline Hora de la lesión & & & $3-5 \%$ & 10 & 4,9 \\
\hline$<12 \mathrm{AM}$ & 30 & 14,7 & Profundidad & & \\
\hline 12 AM-3 PM & 44 & 21,6 & Superficial & 5 & 2,5 \\
\hline 4 PM-7 PM & 59 & 28,9 & Intermedia & 187 & 91,6 \\
\hline $8 \mathrm{PMy}+$ & 71 & 34,8 & Profunda & 12 & 5,9 \\
\hline Agente & & & Tratamiento médico & & \\
\hline Líquidos calientes & 164 & 80,4 & Curación + aditamento & 77 & 37,8 \\
\hline Objetos calientes & 30 & 14,7 & Curación sola & 37 & 18,1 \\
\hline Otros & 10 & 4,9 & No consignado & 90 & 44,1 \\
\hline Días de evolución & & & Tratamiento casero & & \\
\hline Uno & 74 & 36,2 & Sin tratamiento & 41 & 20,1 \\
\hline Dos & 75 & 36,8 & Agua sola & 133 & 65,2 \\
\hline Tres & 55 & 27,0 & Otros $^{* *}$ & 30 & 14,7 \\
\hline \multicolumn{6}{|l|}{ Primera consulta } \\
\hline Centro de salud & 201 & 98,5 & & & \\
\hline Otros* & 3 & 1,5 & & & \\
\hline
\end{tabular}

Tabla 2. Especies bacterianas aisladas en muestras de piel sana y piel quemada provenientes de 204 niños atendidos en COANIQUEM, Santiago de Chile

\begin{tabular}{|lccccc|} 
Aislados bacterianos & \multicolumn{5}{c}{ Muestra } \\
& \multicolumn{2}{c}{ Piel sana } & Piel quemada & Valores p* \\
S. epidermidis & 72 & 52,2 & 63 & 48,1 & 0,251 \\
S. coagulasa (-) & 54 & 39,1 & 48 & 36,6 & 0,336 \\
S. aureus & 9 & 6,5 & 14 & 10,7 & 0,109 \\
S. grupo viridans & 3 & 2,2 & 6 & 4,6 & 0,136 \\
\hline Total & 138 & 100 & 131 & 100 & \\
\hline No significativo. & & & & \\
\hline
\end{tabular}


presentaron similares porcentajes de susceptibilidad a los antimicrobianos, respecto de aquellas aisladas de piel sana $(\mathrm{p}>0,05)$. Cabe destacar el menor porcentaje de susceptibilidad a eritromicina en las cepas de Staphylococcus coagulasa negativa, respecto de $S$. aureus (Tabla 5).
Sobre $90 \%$ de las cepas de S. aureus aisladas desde muestras de piel quemada fueron sensibles a oxacilina, no encontrándose diferencias respecto de la susceptibilidad de las cepas aisladas desde piel sana.

\section{Discusión}

Tabla 3. Recuento bacteriano en piel quemada y piel sana en niños atendidos en COANIQUEM, Santiago, Chile

\begin{tabular}{|c|c|c|c|c|c|}
\hline \multirow{2}{*}{$\begin{array}{l}\text { Recuento bacteriano } \\
\left(\mathrm{ufc} / 10,5 \mathrm{~cm}^{2}\right)\end{array}$} & \multicolumn{2}{|c|}{ Piel sana } & \multicolumn{3}{|c|}{ Piel quemada } \\
\hline & $\mathrm{n}$ & $\%$ & $n$ & $\%$ & \\
\hline Sin desarrollo & 68 & 33 & 79 & 37,6 & \\
\hline $1-99$ & 51 & 24,8 & 42 & 20,0 & p: 0,03 \\
\hline $100-999$ & 45 & 21,8 & 37 & 17,6 & \\
\hline $1.000-9.999$ & 27 & 13,1 & 34 & 16,2 & \\
\hline $10.000-99.000$ & 11 & 5,3 & 18 & 8,6 & \\
\hline $100.000 y+$ & 4 & 2 & - & - & \\
\hline Total & 206 & 100 & 210 & 100 & \\
\hline
\end{tabular}

Tabla 4. Recuento bacteriano en piel quemada según profundidad en niños atendidos en COANIQUEM, Santiago, Chile

\begin{tabular}{|c|c|c|c|c|c|}
\hline \multirow{2}{*}{$\begin{array}{l}\text { Profundidad de la } \\
\text { quemadura }\end{array}$} & \multicolumn{4}{|c|}{ Recuento bacteriano (ufc/10,5 $\mathrm{cm}^{2}$ ) } & \multirow[t]{2}{*}{ Tota } \\
\hline & $\mathrm{n}$ & $\%$ & $n$ & $\%$ & \\
\hline Superficial & 21 & 61,8 & 13 & 38,2 & 34 \\
\hline Intermedia y profunda & 134 & 78,8 & 36 & 21,2 & 170 \\
\hline Total & 155 & 76 & 49 & 24 & 204 \\
\hline
\end{tabular}

La piel es una barrera de defensa fundamental contra la invasión microbiana. El constante equilibrio existente entre la integridad de la piel del hospedero y la microbiota normal previene de forma muy eficiente el desarrollo de infecciones.

Varios estudios evidencian que los tres principales grupos de bacterias grampositivas aisladas desde la piel son: Staphylococcus spp., Micrococcus spp. y corinefor$\mathrm{mes}^{8-10}$. En este estudio no se aislaron Micrococcus ni corineformes desde las muestras de piel sana, ni desde las muestras de piel quemada.

El gran problema de las muestras obtenidas mediante hisopado es la enorme variabilidad existente en la obtención de la muestra. Dicha variabilidad abarca todos los aspectos, a saber: tamaño de la superficie a estudiar, presión que se infringe a la tórula al momento de tomar la muestra, número de veces que se frota la tórula sobre la superficie, lavado o no lavado con suero fisiológico estéril previo a su obtención, motivo por el cual resulta difícil comparar los hallazgos microbiológicos obtenidos en los distintos estudios ${ }^{1}$. Ninguna metodología de obtención de muestra mediante hisopado ha mostrado ser superior a otra en lo que a recuperación de microorganismos se refiere y por lo mismo es que no existe consenso respecto de cual es el método a utilizar.

Las variables antes mencionadas podrían influir en los resultados de nuestro estudio. Sin embargo, dado que la colonización bacteriana que precede a la infección de las

\begin{tabular}{|c|c|c|c|c|c|c|}
\hline \multirow[t]{2}{*}{ Antimicrobiano } & \multicolumn{3}{|c|}{ Piel sana } & \multicolumn{3}{|c|}{ Piel quemada } \\
\hline & $\begin{array}{c}\text { S. coagulasa (-) } \\
(\mathrm{n}: 50)\end{array}$ & $\begin{array}{c}\text { S. epidermidis } \\
\text { (n: 72) }\end{array}$ & $\begin{array}{l}\text { S. aureus } \\
(n: 9)\end{array}$ & $\begin{array}{c}\text { S. coagulasa (-) } \\
(\mathrm{n}: 48)\end{array}$ & $\begin{array}{c}\text { S. epidermidis } \\
(\mathrm{n}: 63)\end{array}$ & $\begin{array}{l}\text { S. aureus } \\
\text { (n: 14) }\end{array}$ \\
\hline Cotrimoxazol & 74 & 68,1 & 88,9 & 81,3 & 84,1 & 100 \\
\hline Gentamicina & 98 & 97,2 & 98 & 97,9 & 100 & 100 \\
\hline Amoxicilina/ ácido clavulánico & 88 & 91,7 & 77,8 & 87,5 & 88,9 & 78,6 \\
\hline Oxacilina & 62 & 72,2 & 88,9 & 77,1 & 85,7 & 92,9 \\
\hline Tetraciclina & 88 & 90,3 & 100 & 83,3 & 92,1 & 92,9 \\
\hline Clindamicina & 96 & 95,8 & 88,9 & 93,8 & 100 & 100 \\
\hline Eritromicina & 34 & 37,5 & 77,8 & 43,8 & 41,3 & 78,6 \\
\hline Ciprofloxacina & 98 & 100 & 88,9 & 100 & 100 & 100 \\
\hline
\end{tabular}


quemaduras de manejo ambulatorio ha sido escasamente estudiada, consideramos que nuestros datos constituyen el primer acercamiento al conocimiento de la microbiota en esta situación.

En 38,7\% de las muestras obtenidas desde la zona quemada no se observó desarrollo bacteriano, posiblemente por el daño de los queratocitos. Se sabe que el estrato córneo proporciona una barrera rígida con el ambiente externo. La descamación de los queratinocitos muertos o una noxa como quemadura interfiere con la colonización bacteriana. Otra posible explicación para la ausencia de desarrollo puede ser el uso previo de antimicrobianos tópicos y las variables asociadas a la toma de la muestra de superficie comentada anteriormente. En el 61,3\% restante presentó principalmente desarrollo de S. epidermidis y otras especies de Staphylococcus coagulasa negativa.

Se ha descrito que durante la quemadura las bacterias localizadas en los folículos pilosos y glándulas sudoríparas pueden sobrevivir a la quemadura; en un estudio de recuento bacteriano en muestras de biopsias de tejido quemado se observó en algunos pacientes, recuentos similares entre el tejido quemado y tejido sano $\left(10^{3} \mathrm{ufc} /\right.$ gramo de biopsia $)^{12}$.

En este estudio los recuentos bacterianos obtenidos en piel sana fueron similares a los obtenidos en piel quemada. Sin embargo, al analizar el subgrupo de muestras con recuentos bacterianos entre uno y $999 \mathrm{ufc} / 10,5 \mathrm{~cm}^{2}$ se observó que la proporción de dicho recuento en piel sana fue significativamente superior al de la piel quemada $(\mathrm{p}=0,024)$.

Al relacionar la profundidad de la quemadura con el recuento bacteriano, se observó que las lesiones por quemadura intermedias o profundas presentaron una marcada tendencia a tener recuentos bacterianos menores que los encontrados en lesiones superficiales, encontrándose una diferencia significativa $(p=0,034)$. Esta situación era esperable, puesto que quemaduras profundas destruyen los queratinocitos, interfiriendo con la colonización bacteriana, fundamentalmente por ausencia de receptores.

La piel intacta y la presencia de microbiota normal son factores fundamentales en la defensa de la colonización por microorganismos patógenos. Otros factores importantes son: la baja humedad de la piel y el $\mathrm{pH}$ ácido de 5 generado por la producción de ácidos grasos libres durante la cornificación. Este último limita el desarrollo de $S$. aureus, el cual crece mejor en un $\mathrm{pH}$ neutro ${ }^{13,14}$.

Sólo en 14 muestras de piel quemada y en 9 muestras de piel sana hubo desarrollo de $S$. aureus, y en recuentos bajos, lo cual podría corresponder a colonización transitoria, dado que $S$. aureus no es parte de la microbiota normal. Ninguno de estos pacientes desarrolló posteriormente infección por este patógeno. Por otro lado, la presencia importante de S. epidermidis en casi todos los pacientes, el cual se une a los receptores de los queratinocitos, y bloquea la adhesión de S. aureus, a través de un proceso conocido como interferencia bacteriana, podría explicar el reducido número de casos en que se aisló S. aureus ${ }^{15,16}$.

Dentro de los bacilos que colonizan la piel, uno de los géneros más prevalentes es Propionibacterium, anaerobio estricto, que no fue contemplado en este estudio. Como ya fue mencionado anteriormente, otra de las probables limitaciones de esta investigación, fue la obtención de la muestra mediante tórula; sin embargo, un estudio realizado por biología molecular determinó que los resultados obtenidos por tórula, curetaje o toma de biopsia, fueron similares ${ }^{17}$.

Este estudio se limitó a evidenciar bacterias aerobias y anaerobias facultativas que se desarrollan en los medios de cultivo que se utilizan de rutina. Al respecto, algunos estudios de biología molecular que contemplan RPC y secuenciación, están comenzando a revelar la variabilidad de comunidades bacterianas presentes en la piel. Sin embargo, tanto los estudios moleculares como los cultivos tradicionales muestran un core set de grupos bacterianos encontrados en la piel, que incluye a S. epidermidis y otros Staphylococcus coagulasa negativa, entre los más relevantes ${ }^{18-23}$.

En este estudio no se detectó la colonización por microorganismos oportunistas y/o patógenos que se detecta precozmente en los pacientes quemados que requieren de hospitalización. Sin lugar a dudas, la limitada extensión de las quemaduras analizadas en este estudio $(\leq 2 \%)$ explica que la piel pueda seguir comportándose como una eficiente barrera de defensa frente a la infección, así como el mantenimiento de la microbiota normal.

Sobre $90 \%$ de las cepas de S. aureus aisladas desde muestras de piel quemada fueron sensibles a oxacilina, no encontrándose diferencias respecto de la susceptibilidad de las cepas aisladas desde piel sana, situación diametralmente opuesta a lo observado en pacientes quemados que se hospitalizan, en quienes la colonización por $S$. aureus resistente a meticilina, así como por bacilos gramnegativos oportunistas, ocurre en unas pocas horas, lo cual pone de manifiesto la peligrosidad del ambiente intrahospitalario.

\section{Resumen}

La colonización bacteriana de la piel de pacientes quemados, sin infección y de manejo ambulatorio, ha sido escasamente estudiada. Objetivo: Cuantificar e identificar el tipo de bacterias que colonizan las zonas cruentas y las zonas sanas de localización homóloga de la piel, en niños entre uno y 15 años de edad que son tratados de forma ambulatoria en la Corporación de Ayuda al Niño Quemado (COANIQUEM) en Santiago de Chile. Pacientes y Métodos: Se estudiaron 204 pacientes quemados en los 
que se tomó una muestra para cultivo desde la zona de la quemadura y otra desde el sitio homólogo sin quemadura. Resultados: Las especies bacterianas aisladas desde ambos tipos de muestra fueron similares: Staphylococcus epidermidis; otras especies de Staphylococcus coagulasa negativa; Staphylococcus aureus, y Streptococcus grupo viridans. El recuento bacteriano de uno a 999 ufc/ 10,5 $\mathrm{cm}^{2}$ fue significativamente superior en las muestras de piel sana $(p=0,0359)$. La asociación entre mayor profundidad de la lesión y el menor recuento bacteriano obtuvo un $\mathrm{p}$ $=0,034$. Conclusión: En niños quemados de entre uno y 15 años, de manejo ambulatorio, los microorganismos que colonizan la zona quemada fueron los mismos que colonizan la piel sana, pero en recuento inferior.

\section{Referencias}

1.- De Oliveira A, Guedes A, Martins da Costa, Ribeiro R, Salles P, Costa L, et al. Cap 25: Infecçao na Criança Queimada. Tratado de Queimaduras. Maciel E, Serra MC. Editores. Ed. Atheneu. Sao Paul-Brasil. 2004; p. 159-165.

2.- De Araújo A. Cap 24: Infecçcao no Paciente Queimado. Tratado de Queimaduras. Maciel E, Serra M C., editores. Ed Atheneu. Sao PaulBrasil. 2004; p. 149-158.

3.- Uppal S K, Ram S, Kwatra B, Garg S, Gupta R. Comparative evaluation of surface swab and quantitative full thickness wound biopsy culture in burn patients. Burns 2007; 33: 460-3.

4.- Benaim F. Quemaduras. Normas para la atención de urgencia. primeras 48 horas de evolución. Rev Arg Quemaduras 1993; 8: 65-72.

5.- Bendlin A, Linares HA y Benaim F. Tratado de Quemaduras. Ed. Interamericana-McGraw-Hill. 1993.

6.- Benaim F. Consideraciones sobre la evaluación de la gravedad de las quemaduras. Rev Arg Quemaduras 2004; 18: 26-30.

7. - Cockerill F, Matthew W, Bush K, Dudley M, Eliopoulus G, Hardy D, et al. Performance Standards for Antimicrobial Susceptibility
Testing; Twentieth Informational Supplement, (June 2010 Update), M100-S20U. Clinical and Laboratory Standards Institute.

8. - Leyden J J, McGinley K J, Nordstrom K M, Webster G F. Skin microflora. J Invest Dermatol 1987; 88 (3 Suppl): 65S-72S.

9. - Roth R R, James W D. Microbiology of the skin: resident flora, ecology, infection. J Am Acad Dermatol 1989; 20: 367-90.

10.- Noble W C. Skin bacteriology and the role of Staphylococcus aureus in infection. Br J Dermatol 1998; 139 Suppl 53: 9-12.

11.- Bowler P G, Duerden B I, Armstrong D G. Wound microbiology and associated approaches to wound management. Clin Microbiol Rev 2001; 14: 244-69.

12.- Ganatra M A, Ganatra H A. Method of quantitative bacterial count in burn wound. Pak J Med Sci 2007; 23: 415-9.

13.- Fluhr J W, Kao J, Jain H, Ahn S K, Feingold K R, Elias P M. Generation of free fatty acids from phospholipids regulates stratum corneum acidification and integrity. J Invest Dermatol 2001; 117: 44-51.

14. - Harder J, Bartels J, Christophers E, Schroder $\mathrm{J}$ M. A peptide antibiotic from human skin. Nature 1997; 387: 861

15. - Bibel D J, Aly R, Bayles C, Strauss W G, Shinefield H R, Maibach H I. Competitive adherence as a mechanism of bacterial interference. Can J Microbiol 1983; 29: 700-3.

16. - Cole G W, Silverberg N L. The adherence of Staphylococcus aureus to human corneocytes. Arch Dermatol 1986; 122: 166-9.

17. - Grice E A, Kong H H, Renaud G, Young A $\mathrm{C}$, NISC Comparative sequencing program, Bouffard G G, et al. A diversity profile of the human skin microbiota. Genome Res 2008;18: 1043-50.

18.- Kloos W E, Bannerman T L. Update on clinical significance of coagulase-negative staphylococci. Clin Microbiol Rev 1994; 7: 11740.

19.- Fredricks D N. Microbial ecology of human skin in health and disease. J Investig Dermatol Symp Proc 2001; 6: 167-9.

20.- Roth R R, James W D. Microbial ecology of the skin. Annu Rev Microbiol. 1988; 42: 441-64.

21.- Cogen A L, Nizet V, Gallo R L. Skin microbiota: a source of disease or defence? Br J Dermatol 2008; 158: 442-55.

22.- Gao Z, Tseng C H, Pei Z, Blaser M J. Molecular analysis of human forearm superficial skin bacterial biota. Proc Natl Acad Sci USA 2007; 104: 2927-32.

23.- Chiller K, Selkin B A, Murakawa G J. Skin microflora and bacterial infections of the skin. J Investig Dermatol Symp Proc 2001; 6: 170-4. 